\title{
A Novel Approach to the Bioluminescent Detection of the SARS-CoV-2 ORF1ab Gene by Coupling Isothermal RNA Reverse Transcription Amplification with a Digital PCR Approach
}

\author{
Zhongjie Fei ${ }^{D}$, Rongbin Wei, Chu Cheng and Pengfeng Xiao * \\ State Key Laboratory of Bioelectronics, School of Biological Science and Medical Engineering, \\ Southeast University, Nanjing 210096, China; 230189585@seu.edu.cn (Z.F.); 230179152@seu.edu.cn (R.W.); \\ 230208215@seu.edu.cn (C.C.) \\ * Correspondence: xiaopf@seu.edu.cn; Tel.: +86-139-5107-9804
}

check for updates

Citation: Fei, Z.; Wei, R.; Cheng, C.; Xiao, P. A Novel Approach to the Bioluminescent Detection of the SARS-CoV-2 ORF1ab Gene by Coupling Isothermal RNA Reverse Transcription Amplification with a Digital PCR Approach. Int. J. Mol. Sci. 2021, 22, 1017. https://doi.org/ 10.3390/ijms22031017

Received: 2 December 2020

Accepted: 18 January 2021

Published: 20 January 2021

Publisher's Note: MDPI stays neutral with regard to jurisdictional claims in published maps and institutional affiliations.

Copyright: (c) 2021 by the authors. Licensee MDPI, Basel, Switzerland. This article is an open access article distributed under the terms and conditions of the Creative Commons Attribution (CC BY) license (https:// creativecommons.org/licenses/by/ $4.0 /)$.

\begin{abstract}
The COVID-19 pandemic caused by the SARS-CoV-2 virus, which first emerged in December 2019, represents an ongoing global public health emergency. Here, we developed an improved and highly sensitive approach to SARS-CoV-2 detection via coupling bioluminescence in real-time (BART) and reverse-transcriptase loop-mediated amplification (RT-LAMP) protocols (RT-LAMPBART) and was also compatible with a digital LAMP system (Rainsuit), which did not allow for real-time quantification but did, nonetheless, facilitate absolute quantification with a comparable detection limit of $10^{4}$ copies/mL. Through improving RNA availability in samples to ensure the target RNA present in reaction, we additionally developed a simulated digital RT-LAMP approach using this same principle to enlarge the overall reaction volume and to achieve real-time detection with a limit of detection of 10 copies $/ \mathrm{mL}$, and with further improvements in the overall dynamic range of this assay system being achieved through additional optimization.
\end{abstract}

Keywords: SARS-CoV-2; accurate and rapid identification; RT-LAMP-BART; digital PCR system; digital RT-LAMP approach

\section{Introduction}

COVID-19 (coronavirus disease 2019) is a pandemic disease caused by SARS-CoV-2 (severe acute respiratory syndrome coronavirus-2) [1] that represents a serious public health emergency throughout the world. Nucleic acid-based diagnostic testing has played a central role in early patient diagnosis and contact tracing efforts [1-3].

Several different approaches to nucleic acid-based SARS-CoV-2 detection have been published to date [4-10]. For example, CRISPR/Cas-based approaches have been developed that can detect RNA samples containing over $1 \times 10^{4}-1 \times 10^{5}$ copies $/ \mathrm{mL}$ (SHERLOCK) or $1 \times 10^{4}$ copies $/ \mathrm{mL}$ (DETECTR) of viral RNA within $1 \mathrm{~h}$. However, these novel approaches are often relatively complex and/or require access to expensive instrumentation without providing sufficient sensitivity advantages relative to more traditional detection techniques such as RT-LAMP [11]. As such these approaches are generally not convenient or conducive to widespread use.

LAMP assays are rapid, sensitive, and specific [12,13], and are more tolerant to the PCR inhibitors that are commonly detected in clinical samples [14-16], reducing the requirement for rigorous sample clean-up and DNA extraction (Figure 1A). The theoretical throughput of such LAMP assays can be enhanced using lab-chips. A given LAMP assay utilizes six specific primers and a strand-displacing Bst DNA polymerase to amplify up to $10^{20}$ copies of a target DNA sequence within $1 \mathrm{~h}$. In addition to being highly tolerant of assay inhibitors, LAMP assays can be conducted at a single constant temperature $\left(65^{\circ} \mathrm{C}\right)$, eliminating the requirement for complex sample preparation or access to a thermocycler while yielding 
sensitive, specific, and robust results [17-20]. We have also previously optimized a LAMPBART technique by utilizing 2-deoxyadenosine-5-( $\alpha$-thio)-triphosphate (dATP $\alpha$ S) instead of deoxyadenosine triphosphate (dATP), thereby yielding a constant background signal and eliminating high levels of false-positive signals when conducting this assay [21].

A

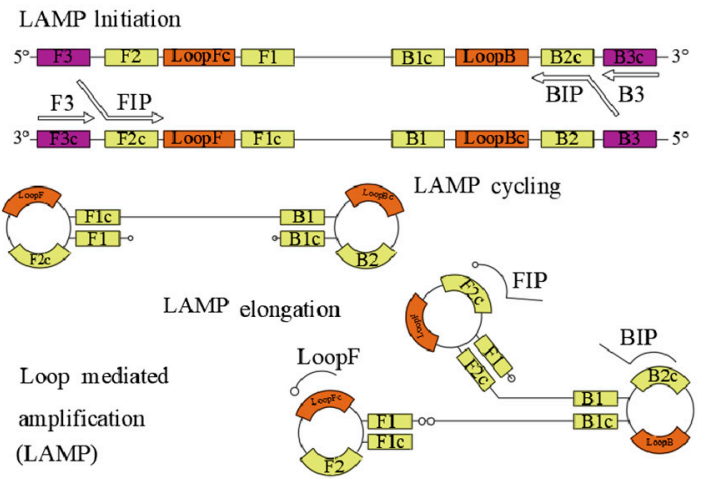

B

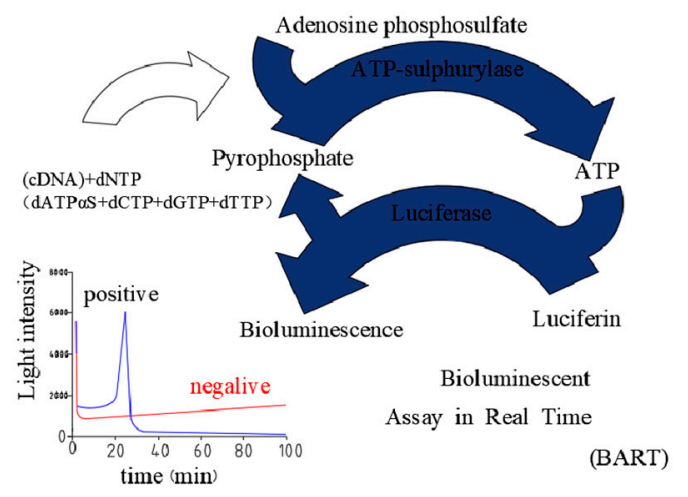

Figure 1. RT-LAMP-BART and LAMP assay principles. (A) RT-BART schematic. (B) LAMP schematic.

Bioluminescence in real-time (BART)-based techniques, in contrast, enable the convenient, rapid, and sensitive detection of specific DNA sequences without the need for complex instrumentation while offering significant sensitivity advantages over similar reverse-transcriptase loop-mediated amplification (RT-LAMP)-based rapid detection approaches $[17,22]$. In this study, we explored the utility of an RT-LAMP-BART detection strategy that is capable of detecting the bioluminescent signal generated by LAMP-derived pyrophosphate in real-time, thereby further amplifying the underlying nucleic acid signal to yield an assay that is more sensitive than other similar pyrophospholuminescent assays. (Figure 1B) [23,24] The theoretical amount of inorganic pyrophosphate (PPi) generated via PCR from a single copy of a 50 base pair DNA template over 23 PCR cycles is $8.4 \times 10^{-14} \mathrm{~mol}\left(2 \times 500 \times 2^{23} / 6 \times 10^{23}=8.4 \times 10^{-14}\right)$, which is significantly higher than the pyrophosphate detection limit $\left(1.56 \times 10^{-15} \mathrm{~mol}\right)[25,26]$. LAMP has a significantly higher amplification efficiency relative to PCR, and as such a LAMP-BART approach offers significant sensitivity and efficiency advantages, theoretically enabling the detection of a single copy of template DNA [14,25-27].

However, conventional LAMP-BART-based assays have rarely been combined with dPCR technology to date. In this study, optimized LAMP-BART assays were studied and found to offer advantages over traditional LAMP-BART assays, which are challenging to conduct in a microfluidic context owing to assay-specific parameters.

Digital PCR (dPCR) is an absolute quantification approach that is used to determine the amount of starting low-concentration DNA template based upon the Poisson distribution [28]. Such dPCR approaches utilize individual droplets derived from a given assay sample as an individual microassay, allowing for a high-throughput microfluidic-based approach to analyzing a given sample [23]. This approach is also compatible with multiplexing by using different fluorophores or by varying the fluorescent intensity of a given probe [29-31]. In the present study, we demonstrate the efficacy of an RT-LAMP-BARTbased approach to the amplification and bioluminescent detection of an RNA template in microfluidic droplets. An RNA concentration gradient distributed across a series of droplets was used to demonstrate the dependence of light emission on starting RNA concentration, enabling the user to perform a quantitative, low-volume, high-throughput assay. Overall, in this study, we demonstrate that this RT-LAMP-BART assay can be coupled with a dPCR instrument and a simulated $\mathrm{APCR}$ approach to facilitate the rapid and sensitive detection of the SARS-CoV-2 ORF1ab Gene. 


\section{Results and Discussion}

\subsection{The Relative Feasibility of Using dATP $\alpha$ S Instead of dATP in RT-LAMP Reactions}

For the present study, we adapted RT-LAMP assays targeting the SARS-CoV-2 Orf1ab gene as they have previously been shown to be highly sensitive and specific [32].

To test the feasibility of our optimized RT-LAMP approach, tubes containing conventional or optimized RT-LAMP reagents were combined with the target RNA sequence (tubes containing conventional or optimized RT-LAMP-BART reagents without target RNA sequences were used as a negative control), after which the reaction was heat-activated and maintained at a constant temperature of $65^{\circ} \mathrm{C}$ for $40 \mathrm{~min}$. In the optimized RT-LAMP, dATP was replaced with dATP $\alpha$ S in the RT-LAMP, whereas the other dNTPs were the normal monomers.

Relative to the conventional reagent mixture, the optimized reagent mixture had the same amplification effect in RT-LAMP (Figure 2A), consistent with our previous findings [33] that $\mathrm{dATP} \alpha \mathrm{S}$ can eliminate false positive signal and better facilitate amplification than dATP in LAMP attributable to dATP (Figure 2B). Although this bioluminescent signalbased method could be used to detect SARS-CoV-2, it could not achieve real-time and accurate quantification. Therefore, we tried to combine this method with digital PCR, which has hardly been tried before.

A

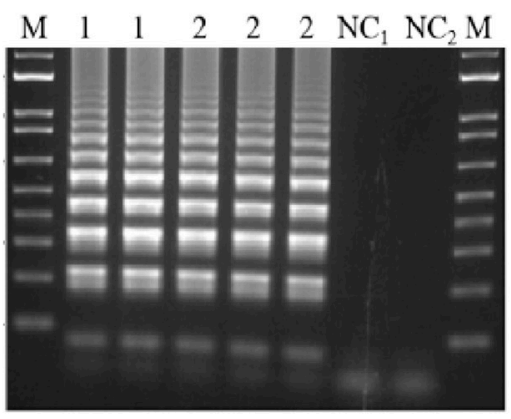

$\mathrm{B}$

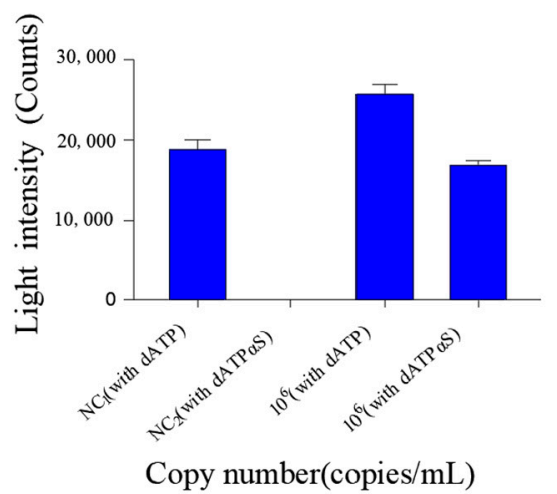

Figure 2. (A) Agarose gel electrophoresis of RT-LAMP products. Lanes $\mathrm{NC}_{1}, 1,2$, and $\mathrm{M}$ correspond to the negative control, $10^{6}$ copies $/ \mu \mathrm{L}$ of the purified template pseudoviral plasmid reference RNA (with dATP), $10^{6}$ copies $/ \mu \mathrm{L}$ of the purified template pseudoviral plasmid reference RNA (with dATP $\alpha$ S) and the marker (DL2000), respectively. (B) Light intensity (counts) of the purified template pseudoviral plasmid reference RNA (with dATP), $10^{6}$ copies $/ \mu \mathrm{L}$ of the purified template pseudoviral plasmid reference RNA (with dATP $\alpha$ S) and the negative control of dATP and dATP $\alpha$ S.

\subsection{Assessment of a Digital RT-LAMP-BART Assay Approach}

We next evaluated the feasibility of a droplet-based digital LAMP-BART assay approach by using target RNA $\left(10^{6}\right.$ copies $\left./ \mathrm{mL}\right)$ together with a conventional or optimized RT-LAMP-BART mixture and the DROPDx-2044HT digital PCR system (Suzhou, Jiangsu, China). This system is able to generate roughly 20,000 stable effective droplets using the Mono Flex droplet generation technology, with a target RNA volume of $0.0005 \mu \mathrm{L}$ per droplet. The stability of the overall reaction system was ensured by using Droplet Generation Oil and Stabilizer. When this approach was conducted with a conventional RT-LAMP-BART reagent mixture in the DROPDx-2044HT digital PCR system, all droplets generated by this system yielded bioluminescence (Figure 3A). This was consistent with the overall assay principle outlined in Figure 1A, wherein PPi is converted to ATP by ATP sulfurylase, with this ATP subsequently generating a bioluminescent signal through the action of the luciferase enzyme. When ATP is present within the reaction mixture, a bioluminescent signal will thus be generated even in the absence of PPi. As dATP is structurally similar to ATP, it can also drive luciferase-mediated luciferin transformation into oxidized luciferin, producing bioluminescence, as confirmed via pyrosequencing [23,24]. As such, all droplets containing the conventional RT-LAMP-BART reagent mixture yielded 
bioluminescent signal even when template concentrations were low, making it impossible to distinguish between positive and negative signals (Figure $3 \mathrm{~A}_{1}, \mathrm{~A}_{2}$ ). In contrast, when the optimized RT-LAMP-BART reagent mixture was used with the DROPDx-2044HT digital PCR system, some droplets exhibited (Figure 3A) bioluminescence whereas others did not (Figure 3B), enabling us to clearly differentiate between positive and negative signals so as to facilitate the counting thereof. As such, our conventional BART reagent mixture was incompatible with this dPCR approach, whereas our optimized RT-LAMP-BART reagent mixture was amenable to use in this assay context.

A

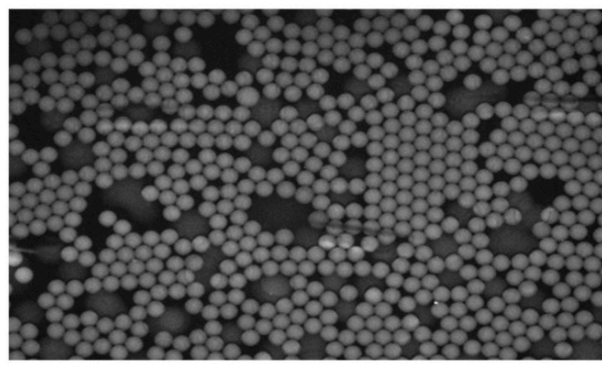

$\mathrm{A}_{1}$

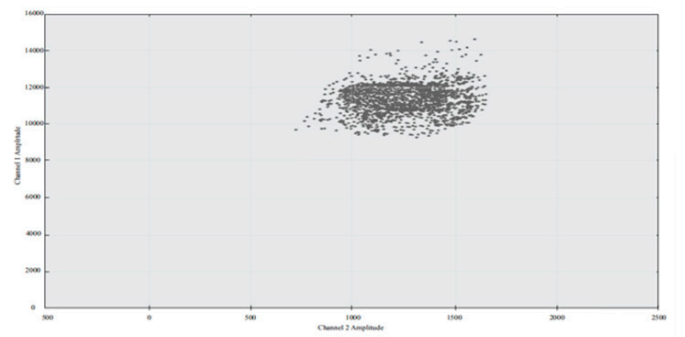

$\mathrm{A}_{2}$
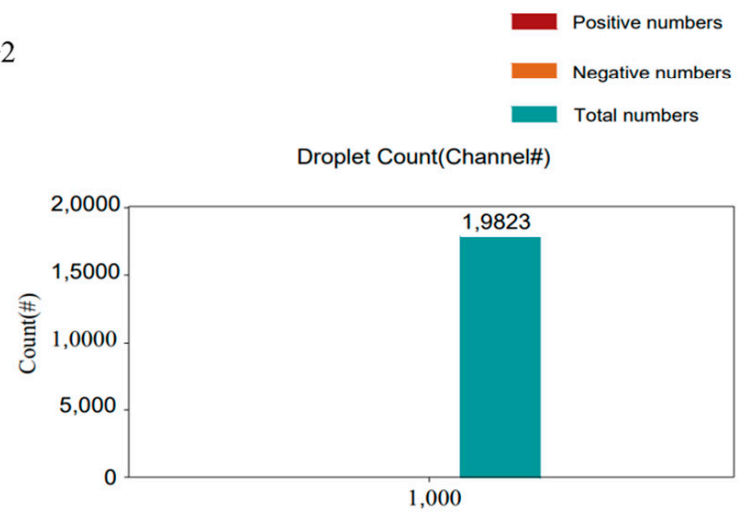

B

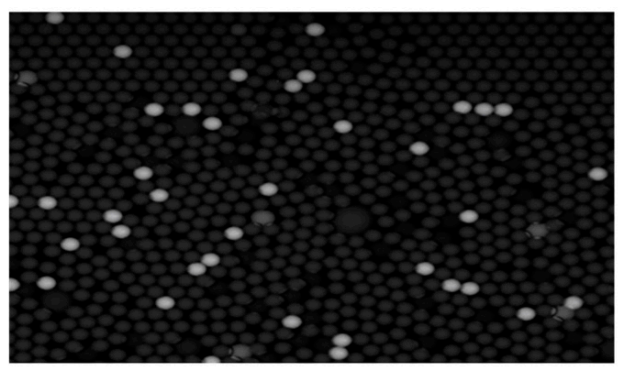

$\mathrm{B}_{1}$

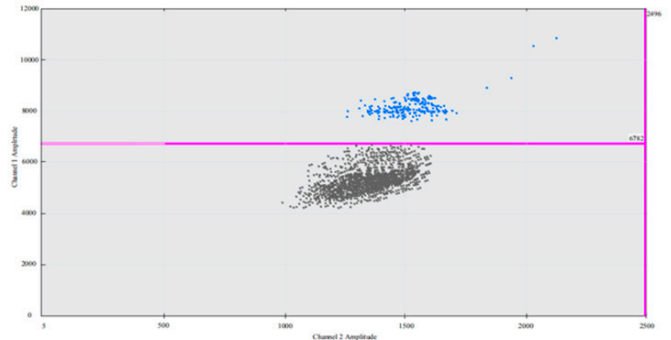

$\mathrm{B}_{2}$

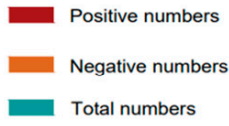

Droplet Count(Channel\#)

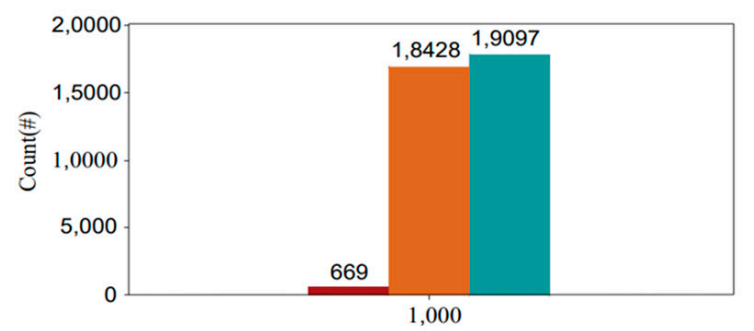

Figure 3. (A) RT-LAMP-BART bioluminescent droplet images prepared using a conventional BART reagent mixture [17]. $\left(\mathbf{A}_{1}\right)$ The distribution of bioluminescent counts in $(\mathbf{A})$. $\left(\mathbf{A}_{\mathbf{2}}\right)$ Droplet count classifications in (A). (B) RT-LAMP-BART bioluminescent droplet images prepared using an optimized BART reagent mixture containing dATP $\alpha$ S rather than dATP.

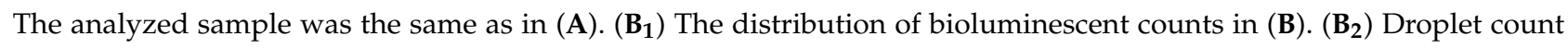
classifications in (B).

To further assess the accuracy and sensitivity of this quantification approach, we next tested this assay using RNA concentrations between $10^{3}$ and $10^{6}$ copies $/ \mathrm{mL}$. The number of droplets that yielded a bioluminescent signal in this assay context increased with increasing sample concentration (Figure $4 \mathrm{~A}-\mathrm{C}$ ), and this was confirmed by counting the number of positive droplets (Figure $4 \mathrm{~A}_{1}-\mathrm{C}_{1}$ ). 

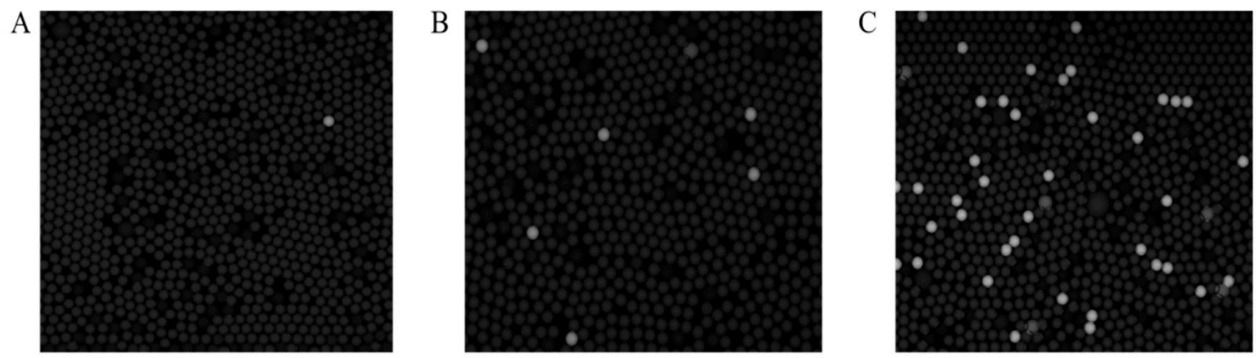

$\mathrm{A}_{1}$

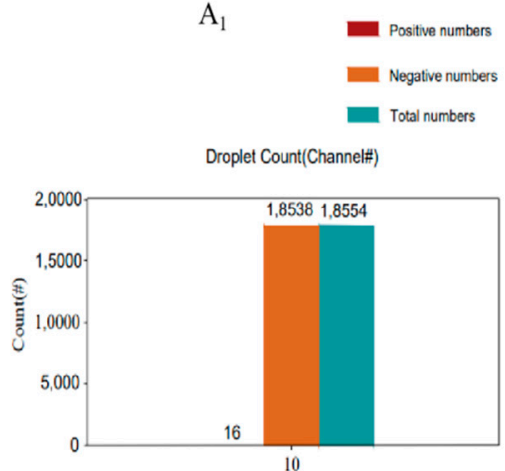

$\mathrm{B}_{1}$

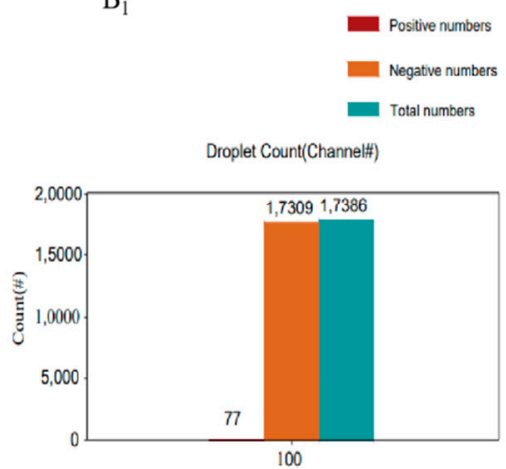

$\mathrm{C}_{1}$

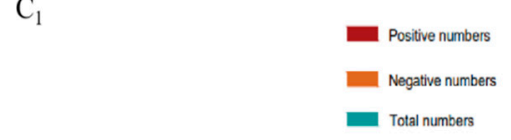

Droplet Count(Channellit)

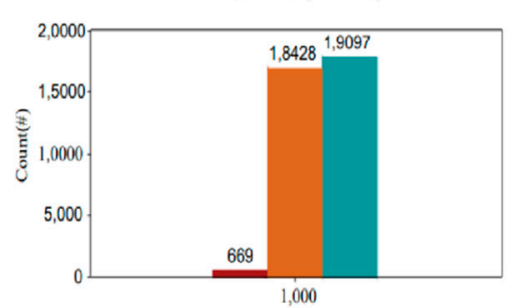

Figure 4. (A) RT-LAMP-BART bioluminescent droplet images prepared using an optimized BART reagent mixture. The target RNA template concentration was $10^{4}$ copies $/ \mathrm{mL}$. ( $\left(\mathbf{A}_{\mathbf{1}}\right)$ Droplet count of the reaction shown in (A). Positive droplets: 9; negative droplets: 19,574; total droplets: 19,583. (B) RT-LAMP-BART bioluminescent droplet images prepared using an optimized BART reagent mixture. The target RNA template concentration was $10^{5}$ copies $/ \mathrm{mL}$. (B $\left.\mathbf{B}_{1}\right)$ Droplet count of the reaction shown in (B). Positive droplets: 77; negative droplets: 17,309; total droplets: 17,386. (C) RT-LAMP-BART bioluminescent droplet images prepared using an optimized BART reagent mixture. The target RNA template concentration was $10^{6}$ copies $/ \mathrm{mL}$. $\left(\mathbf{C}_{\mathbf{1}}\right)$ Droplet count of the reaction shown in $(\mathbf{C})$. Positive droplets: 669; negative droplets: 18,428; total droplets: 19,097.

As shown in Table 1, using the number of copies in a given droplet reaction (target RNA concentration $\times$ reaction volume) and $N$ (the total number of droplets; 20,000 ), the number of copies per droplet $(\lambda)$ could be calculated (Copies per droplet $=-\ln (\mathrm{Nn} / \mathrm{N})=$ Copies in the reaction/Total droplets). Based upon the Poisson distribution, it was thus possible to calculate the number of theoretical positive and negative droplets ( $\mathrm{Np}$ and $\mathrm{Nn}$, respectively) for a given assay setup as follows $(\lambda=-\ln (\mathrm{Nn} / \mathrm{N}))$. At target RNA concentrations of $10^{4}, 10^{5}$, and $10^{6}$ copies $/ \mathrm{mL}$, theoretical $\mathrm{Np}$ values were 10,99 , and 969 , respectively. The actual experimental $\mathrm{Np}$ values at these concentrations $(9,77,669)$ were consistent with these theoretical calculations shown in Table 1 (Figure $\left.4 \mathrm{~A}_{1}-\mathrm{C}_{1}\right)$. The actual RNA concentration was calculated using the $\lambda$ value as follows: $\lambda=-\ln (\mathrm{Nn} / \mathrm{N})=$ Reaction Concentration in (in Copies $/ \mu \mathrm{L}) \times$ droplet volume. Reaction Concentration $=$ $-\ln (\mathrm{Nn} / \mathrm{N}) /$ droplet volume. Furthermore, the observed target RNA concentrations in this assay $(0.98,8.89,70.06$ copies $/ \mu \mathrm{L})$ were consistent with the predicted RNA concentrations $(1,10,100$ copies $/ \mu \mathrm{L})$ across the tested RNA concentration range. When RNA was further diluted to $10^{3}$ copies $/ \mathrm{mL}$, however, the results tended to become inconsistent and often undetectable (data not shown). While this method was able to achieve absolute precise quantification and was very convenient and affordable, it thus had a detection limit of $10^{4}$ copies $/ \mathrm{mL}$ ( 1 copies per reaction), thus offering no advantage over other methods such as the RT-LAMP-BART approach discussed above or CRISPR/Cas-based methods. This was due to an intrinsic limitation of the DROPDx-2044HT digital PCR system wherein the reaction mixture volume was $10 \mu \mathrm{L}$, rather than a consequence of a lack of methodological sensitivity. The theoretical detection limit for this reaction system is $10^{3}$ copies $/ \mathrm{mL}$ ( 1 copy per reaction), but taking just $10 \mu \mathrm{L}$ from a $100 \mu \mathrm{L}$ RT-LAMP-BART reaction mixture caused the copies present within the reaction to become too inconsistent. When testing actual 
clinical samples, we generally use about 100 microliters of ultrapure water to dissolve the extracted RNA or to directly dissolve the collected samples for testing.

Table 1. The accuracy and sensitivity of a bioluminescent signal-based digital LAMP assay.

\begin{tabular}{|c|c|c|c|c|c|c|c|c|}
\hline \multirow{2}{*}{$\begin{array}{l}\text { Target RNA } \\
\text { Concentrations } \\
\text { (Copies/mL) }\end{array}$} & \multirow{2}{*}{$\begin{array}{l}\text { Target RNA Concentrations } \\
\text { in Reaction Mix (Copies/ } \mu \mathrm{L}) \\
\text { (10 } \mu \mathrm{L} \text { Reaction Mixtures) }\end{array}$} & \multicolumn{3}{|c|}{$\begin{array}{l}\text { Theoretical Calculation } \\
(\mathrm{N}=20,000)\end{array}$} & \multicolumn{4}{|c|}{ Actual Results } \\
\hline & & $\lambda$ & $\mathrm{Np}$ & $\mathrm{Nn} / \mathrm{N}$ & $\mathrm{Np}$ & $\mathbf{N}$ & $\lambda$ & $\mathrm{C}($ Copies/ $\mu \mathrm{L})$ \\
\hline $10^{4}$ & 1 & 0.0005 & 10 & 0.9995 & 9 & 18,554 & 0.00049 & 0.98 \\
\hline $10^{5}$ & 10 & 0.0050 & 99 & 0.9950 & 77 & 17,386 & 0.00443 & 8.89 \\
\hline $10^{6}$ & 100 & 0.0500 & 969 & 0.9516 & 669 & 19,097 & 0.03503 & 70.06 \\
\hline
\end{tabular}

$\mathrm{N}$ : the total number of droplets. Np: number of positive droplets. Nn: number of negative droplets. $\lambda$ : copies per droplet $=-\ln (\mathrm{Nn} / \mathrm{N})=$ Copies in the reaction/Total droplets $=$ Concentration in reaction $($ Copies $/ \mu \mathrm{L}) \times \mathrm{V}$ (volume of each droplet). $\mathrm{V}=$ Reaction volume $/ \mathrm{N}=$ $0.0005 \mu \mathrm{L} . \mathrm{P}(0)=\mathrm{Nn} / \mathrm{N}=\mathrm{e}^{-\lambda,} \lambda=-\ln (\mathrm{Nn} / \mathrm{N})=$ Concentration in reaction $\times \mathrm{V}$. Concentration in reaction $=[-\ln (\mathrm{N} / \mathrm{N})] / \mathrm{V}$. Target RNA concentration $=10 \times \mathrm{C}_{\text {Copies } / \mu \mathrm{L}}=10^{43} \times \mathrm{C}_{\text {Copies } / \mathrm{mL}} \cdot \mathrm{P}(0)=\mathrm{Nn} / \mathrm{N}=\mathrm{e}^{-\lambda}, \lambda=-\ln (\mathrm{Nn} / \mathrm{N})=\mathrm{C}_{\text {Copies } / \mathrm{mL}} \times \mathrm{V}$.

However, in conventional RT-LAMP, RT-PCR, digital PCR systems, or biosensor-based detection [34], the RNA sample or DNA volume is $2-5 \mathrm{~mL}$, such that when samples contain low concentrations of RNA the actual RNA may not be present in the reaction. Therefore, while many novel approaches to single copy RNA detection have been developed, they still have a detection limit of $10^{3}-10^{4}$ copies $/ \mathrm{mL}$. This same limitation constrained the digital RT-LAMP-BART assay in the present study. It is thus vital that RNA availability in low concentration samples be improved without altering RT-LAMP reaction efficiency in order to further improve detection limits. In the RT-LAMP reaction system, blind proportional amplification would lead to unstable amplification reaction and decreased sensitivity, while it is combined with digital PCR technology perfectly solved this problem, through dividing a large RT-LAMP reaction system into smaller ones which could increase the utilization rate of template RNA as much as possible in the form of normal RT-LAMP reaction system. If all the template RNA extracted from the sample $(100 \mu \mathrm{L})$ were present in the reaction, this would significantly improve the overall detection limit. To overcome this limitation and improve the utilization of sample RNA, we therefore next developed a well-based simulated digital RT-LAMP-BART protocol. Additionally, this droplet-based digital LAMPBART approach was unable to directly establish the target sample concentration based upon the number of negative signals owing to the uncertainty in the $\mathrm{N}$ (total droplet number) value (Figure $4 \mathrm{~A}_{1}-\mathrm{C}_{1}$ ), leading us to explore the development of a simulated digital RT-LAMP assay capable of doing so in Section 2.3.

\subsection{Assessment of Bioluminescent Signal-Based Quantification in a Simulated Digital RT-LAMP Assay}

Our simulated digital RT-LAMP assay protocol was designed using the same principles as were used for the above bioluminescent-based digital RT-LAMP assay, treating individual wells of a 96-well plate as individual droplets. To improve the utilization of RNA in a given sample, the total RT-LAMP-BART reaction mixture was used for the reaction.

To evaluate the accuracy and sensitivity of this simulated digital bioluminescent RTLAMP assay, we prepared wells containing between 10 and $10^{4}$ copies $/ \mathrm{mL}$ of target RNA. As shown in Table 2, we were able to utilize the number of RNA copies per reaction (Target RNA concentration in each reaction $\times$ reaction volume) and the number of wells $(\mathrm{N}=96)$ to calculate the number of copies per well $(\lambda=$ Copies in the reaction/N). We were then able to calculate the number of theoretical positive and negative wells ( $\mathrm{Np}$ and $\mathrm{Nn}$ ) based upon the Poisson distribution as follows: $\lambda=-\ln (\mathrm{Nn} / \mathrm{N})$. Overall, at RNA concentrations of $10,10^{2}$, $10^{3}$, and $10^{4}$ copies $/ \mathrm{mL}, \mathrm{Np}$ was predicted to be $1,10,62$, and 96 , respectively. The actual observed values $(2,8,58,96)$ were consistent with these predicted values (Figure 5A-D). The actual RNA concentration per well could then be calculated based upon the Nn value. Based on the equation $\lambda=-\ln (\mathrm{Nn} / \mathrm{N})=$ Concentration in reaction $\times \mathrm{V}$ (volume of each well), the relationship between $\mathrm{Nn}$ and RNA concentration (in copies $/ \mu \mathrm{L}$ ) was defined 
as: Concentrations in reaction $=-\ln (\mathrm{Nn} / \mathrm{N}) / \mathrm{V}=-\ln (\mathrm{Nn} / 96) / 10.4=-\ln (\mathrm{Nn} / 96) / 10.4=$ $\ln (96 / \mathrm{Nn}) / 10.4$.

Table 2. The accuracy of the bioluminescent signal-based simulated digital LAMP assay.

\begin{tabular}{|c|c|c|c|c|c|c|c|c|}
\hline \multirow{2}{*}{$\begin{array}{l}\text { Target RNA } \\
\text { Concentrations } \\
\text { (Copies/mL) }\end{array}$} & \multirow{2}{*}{$\begin{array}{c}\text { Target RNA Concentrations in } \\
\text { Reaction (Copies/ } \mu \mathrm{L}) \\
\text { (1000 } \mu \mathrm{L} \text { Reaction Mixtures) }\end{array}$} & \multicolumn{3}{|c|}{$\begin{array}{l}\text { Theoretical Calculation } \\
\qquad(\mathrm{N}=96)\end{array}$} & \multicolumn{4}{|c|}{ Actual Results } \\
\hline & & $\lambda$ & $\mathbf{N p}$ & $\mathbf{N n} / \mathbf{N}$ & $\mathrm{Np}$ & $\mathbf{N}$ & $\lambda$ & $C($ Copies/ $\mu \mathrm{L})$ \\
\hline 10 & 0.001 & 0.0104 & 1 & 0.9896 & 2 & 96 & 0.0208 & 0.0019 \\
\hline $10^{2}$ & 0.01 & 0.1040 & 10 & 0.9019 & 8 & 96 & 0.0870 & 0.0084 \\
\hline $10^{3}$ & 0.1 & 1.0416 & 62 & 0.3535 & 58 & 96 & 0.9268 & 0.0885 \\
\hline $10^{4}$ & 1 & 10.4167 & 96 & 0 & 96 & 96 & $\geq 9.6$ & $\geq 0.96$ \\
\hline
\end{tabular}

$\mathrm{N}$ : the total number of wells. Np: number of positive wells. Nn: number of negative wells. $\lambda$ : copies per well $=-\ln (\mathrm{Nn} / \mathrm{N})=\mathrm{Copies}$ in the reaction $/$ Total wells $=$ Concentration in reaction $($ Copies $/ \mu \mathrm{L}) \times \mathrm{V}($ volume of each well $)$. $\mathrm{V}=$ Reaction volume $/ \mathrm{N}=10.4 \mu \mathrm{L} . \mathrm{P}(0)=$ $\mathrm{Nn} / \mathrm{N}=\mathrm{e}^{-\lambda}, \lambda=-\ln (\mathrm{Nn} / \mathrm{N})=$ Concentration in reaction $\times \mathrm{V}$. Concentration in reaction $=[-\ln (\mathrm{N} / \mathrm{N})] / \mathrm{V}$. Target RNA concentration $=$ $10 \times \mathrm{C}_{\text {Copies } / \mu \mathrm{L}}=10^{4} \times \mathrm{C}_{\text {Copies } / \mathrm{mL}}$.

A

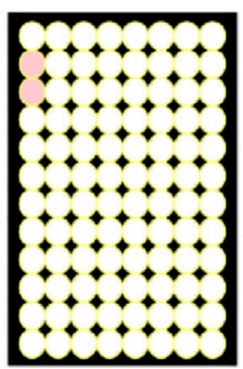

$\mathrm{A}_{1}$

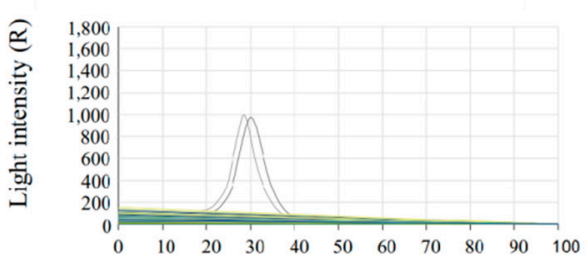

$\mathrm{A}_{2}$

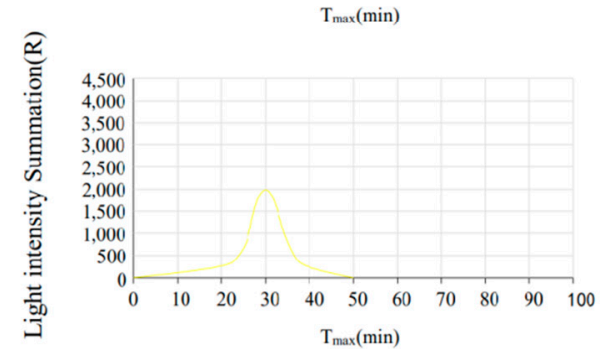

$\mathrm{C}$

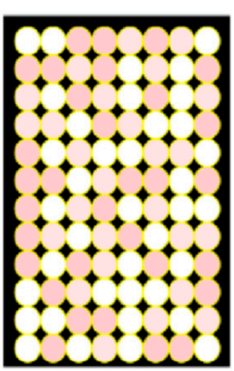

$\mathrm{D}$

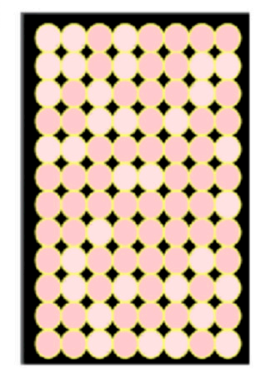

$\mathrm{B}_{1}$

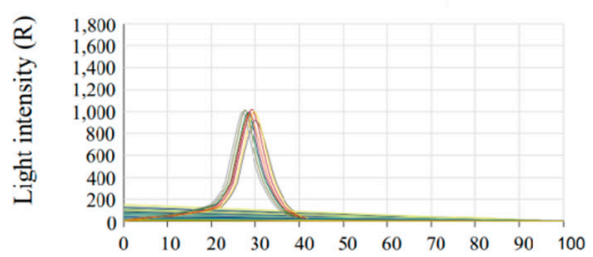

$\mathrm{B}_{2}$

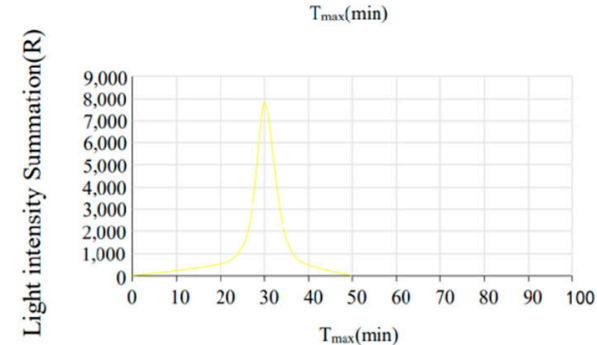

Figure 5. (A) RT-LAMP-BART bioluminescent well images obtained when utilizing an optimized BART reagent mixture. The target RNA template concentration for this plate was 10 copies $/ \mathrm{mL}$. Positive wells: 2 Negative wells: 94 Total wells: 96. (B) RT-LAMP-BART bioluminescent well images obtained when utilizing an optimized BART reagent mixture. The target RNA template concentration for this plate was $10^{2}$ copies $/ \mathrm{mL}$. Positive wells: 8; negative wells: 88 ; total wells: 96. (C) RT-LAMP-BART bioluminescent well images obtained when utilizing an optimized BART reagent mixture. The target RNA template concentration for this plate was $10^{3}$ copies $/ \mathrm{mL}$. Positive wells: 58 ; negative wells: 38; total wells: 96. (D) RT-LAMP-BART bioluminescent well images obtained when utilizing an optimized BART reagent mixture. The target RNA template concentration for this plate was $10^{4}$ copies $/ \mathrm{mL}$. Positive wells: 96 Negative wells: 0 Total wells: 96 . ( $\left.\mathbf{A}_{\mathbf{1}}\right)$ RT-LAMP-BART amplification curve of each well in (A). $\left(\mathbf{A}_{\mathbf{2}}\right)$ The summed RT-LAMP-BART amplification curve for all

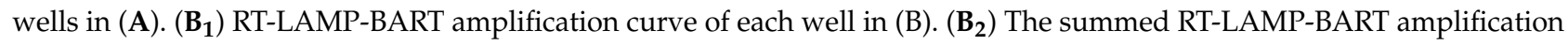
curve for all wells in (B).

The calculated RNA concentrations under these four reaction conditions were 0.09 , $0.084,0.885$, and 9.6 copies $/ \mu \mathrm{L}$, consistent with the predicted concentrations (Table 2: 0.001, 
$0.01,0.1,1$ copies / $\mu$ L. Overall, our simulated digital LAMP assay thus had a sensitivity of 10 copies/mL (Table 2), making it more sensitive than both our digital LAMP and RT-LAMP-BART assays.

While in the tested format this simulated digital LAMP assay had a quantification range of $10-10^{4}$ copies / $\mathrm{mL}$ of target RNA, making it primarily useful for detecting lowconcentration RNA samples. It is a very flexible method, and by adjusting the number of wells (if a machine capable of more parallel wells was designed), it is possible to further expand this precise quantification range (the more wells, the larger precise quantification range). This approach can also improve the overall sensitivity and stability of this assay (if a machine capable of such parallel analysis was designed, this range would expand to $10-(+\infty)$ copies $/ \mathrm{mL})$.

Furthermore, we were also able to use this method for simultaneous real-time and endpoint detection of assay results, which could be acquired in between $15-40$ min (Figure $5 A-A_{2}, B-B_{2}$ ). Each well of a 96-well plate could be detected in real-time (Figure $5 \mathrm{~A}_{1}, \mathrm{~B}_{1}$, and by accumulating these signals we were able to establish the overall bioluminescent signal values for 96 wells in real-time (Figure $5 \mathrm{~A}_{2}, \mathrm{~B}_{2}$ ). By comparing the peaks (about $30 \mathrm{~min}$ ) of light intensity, we were also able to define the RNA concentration. In general, this approach can accurately quantify target RNA levels in real-time, yielding results within $20 \mathrm{~min}$ which greatly reduced the probability of false positives. It is well known that the longer the RT-LAMP reaction time, the higher the probability of false positive [35].

2.4. Assessment of Bioluminescent Signal-Based Quantification in a Simulated Digital RT-LAMP Assay as Verified with a SARS-CoV-2 Orf1ab Visual RT-LAMP Kit

The SARS-CoV-2 Orf1ab Visual RT-LAMP kit was used to verify our simulated digital RT-LAMP assay. Pseudoviral plasmid reference material and negative control samples in the Kit were prepared using a two-step concentration gradient $\left(10^{4}, 10^{3}\right.$ copies $\left./ \mathrm{mL}\right)$ and tested via simulated digital RT-LAMP assay, $\mathrm{qPCR}$, and visual assay. As shown in Figure 6, when the target RNA concentration was $10^{4}$ copies $/ \mathrm{mL}$, the results of all three methods were positive and the qPCR assay took $32 \mathrm{~min}$, whereas the visual RT-LAMP assay required $35 \mathrm{~min}$ and the simulated digital RT-LAMP assay took $20 \mathrm{~min}$. When target RNA concentrations were $10^{3}$ copies $/ \mathrm{mL}$ (reached the detection limit of the SARS-CoV-2 Orf1ab Visual RT-LAMP kit), qPCR, and visual assay became unsteady (sometimes positive while sometimes negative). It was due to the template was not able to actually present in RT-LAMP every time. When the RNA were actually present in RT-LAMP, all three methods again yielded positive results and required 60,65 , and $20 \mathrm{~min}$, respectively. When negative control samples were tested, all three approaches yielded negative results. The results of a simulated digital RT-LAMP assay conducted using positive control samples from the kit (Table 3) were consistent with the results in Table 2.

Table 3. The accuracy of the bioluminescent signal-based simulated digital LAMP assay.

\begin{tabular}{|c|c|c|c|c|c|c|c|c|}
\hline \multirow{2}{*}{$\begin{array}{l}\text { Target RNA } \\
\text { Concentrations } \\
\text { (Copies/mL) }\end{array}$} & \multirow{2}{*}{$\begin{array}{c}\text { Target RNA Concentrations in } \\
\text { Reaction (Copies } / \mu \mathrm{L}) \\
\text { (1000 } \mu \text { L Reaction Mixtures) }\end{array}$} & \multicolumn{3}{|c|}{$\begin{array}{l}\text { Theoretical Calculation } \\
\qquad(\mathrm{N}=96)\end{array}$} & \multicolumn{4}{|c|}{ Actual Results } \\
\hline & & $\lambda$ & $\mathrm{Np}$ & $\mathrm{Nn} / \mathrm{N}$ & $\mathrm{Np}$ & $\mathbf{N}$ & $\lambda$ & $\mathrm{C}($ Copies $/ \mu \mathrm{L})$ \\
\hline 0 & 0 & 0 & 0 & 1 & 0 & 96 & 0 & 0 \\
\hline $10^{3}$ & 0.1 & 1.0416 & 62 & 0.3535 & 60 & 96 & 0.9808 & 0.0943 \\
\hline $10^{4}$ & 1 & 10.4166 & 96 & 0 & 96 & 96 & $\geq 9.6$ & $\geq 9.6$ \\
\hline
\end{tabular}

$\mathrm{N}$ : the total number of wells. Np: number of positive wells. Nn: number of negative wells. $\lambda$ : copies per well $=-\ln (\mathrm{Nn} / \mathrm{N})=\mathrm{Copies}$ in the reaction $/$ Total wells $=$ Concentration in reaction $($ Copies $/ \mu \mathrm{L}) \times \mathrm{V}$ (volume of each well) $\mathrm{V}=$ Reaction volume $/ \mathrm{N}=10.4 \mu \mathrm{L}$. $\mathrm{P}(0)=$ $\mathrm{Nn} / \mathrm{N}=\mathrm{e}^{-\lambda}, \lambda=-\ln (\mathrm{Nn} / \mathrm{N})=$ Concentration in reaction $\times \mathrm{V}$. Concentration in reaction $=[-\ln (\mathrm{N} / \mathrm{N})] / \mathrm{V}$. Target RNA concentration $=$ $10 \times \mathrm{C}_{\text {Copies } / \mu \mathrm{L}}=10^{4} \times \mathrm{C}_{\text {Copies }} / \mathrm{mL}$. 
A

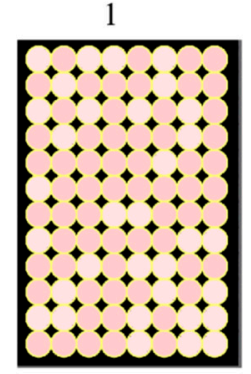

2

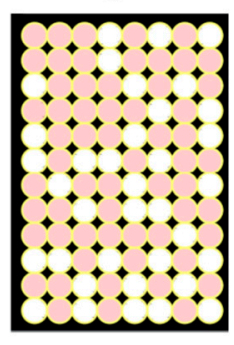

C

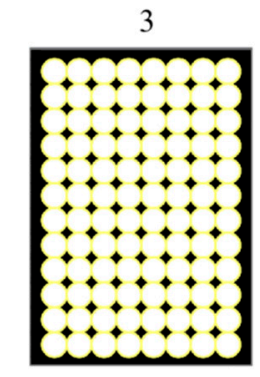

B
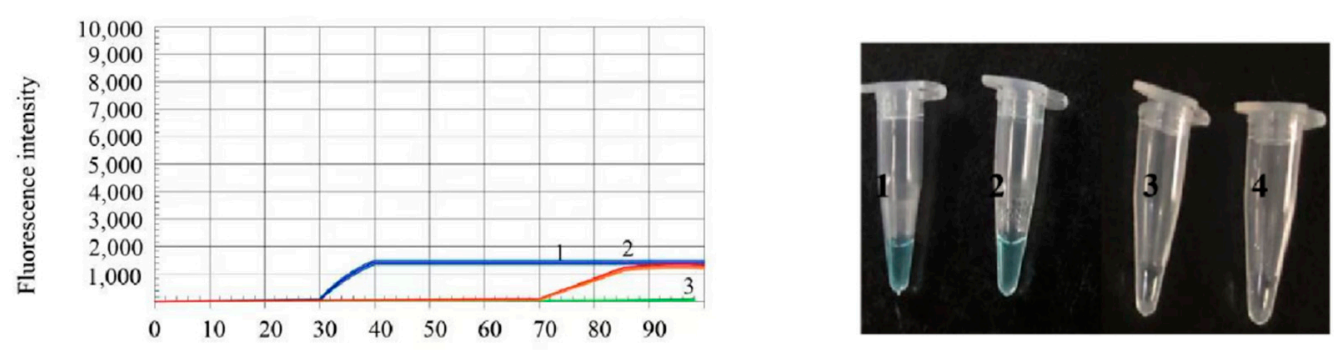

Time(min)

Figure 6. (A) RT-LAMP-BART bioluminescent well images obtained when utilizing an optimized BART reagent mixture. 1 and 2 meant the target RNA template concentration from $10^{4}$ to $10^{3}$ copies $/ \mathrm{mL}$. 3 meant the negative control sample. Positive wells from 1 to 3: 96, 60, 0. Negative wells from 1 to 3: 0, 30, 96. The total well wells from 1 to 3: 96, 96, 96. (B) The same samples in (A) were tested by qPCR. (C) The same samples in (A) were tested via a colorimetric kit, wherein blue and clear correspond to positive and negative, respectively. The negative control sample was derived from the SARS-CoV-2 Orflab Visual RT-LAMP Kit.

2.5. The Specificity and Assessments of Bioluminescent Signal-Based Quantification in a Simulated Digital RT-LAMP Assay as Verified with RT-qPCR

As shown in Table 4, in combination with the results of simulated digital RT-LAMP assay and RT-qPCR, we found that digital PCR has good specificity and required less time and cost less. The advantages of this method, which are high sensitivity, quantitative accuracy and speed outweigh the disadvantages of its more complicated protocol and operation. In terms of cost, this method has an advantage over fluorescence detection because it does not require an excitation source. However, because it is combined with digital PCR, the cost is not low. However, as the equipment upgrades, the operation will be simplified, and the cost can be further reduced. In general, this method is of great significance in accurate detection and sequencing of various viruses.

Table 4. Ct of qPCR products produced from different copies of standard plasmid pMD18T-S.

\begin{tabular}{cccc}
\hline \multirow{2}{*}{ Methods } & \multicolumn{3}{c}{ Results } \\
\cline { 2 - 4 } & Positive & Negative & Minutes for Positive Call \\
\hline qPCR & 9 & 11 & $48 \mathrm{~min}$ \\
simulated digital PCR & 9 & 11 & $30 \mathrm{~min}$ \\
\hline
\end{tabular}

\section{Materials and Methods}

\subsection{Reagents}

A pseudoviral SARS-CoV-2 ORF1ab reference plasmid was synthesized by Sangon Biotech (Shanghai, China), and contained the complete SARS-CoV-2 ORF1ab gene sequence. SARS-CoV-2 Orf1ab Visual RT-LAMP Kits were obtained from Biolab (Beijing, China). Adenosine 5' -phosphosulfate (APS), adenosine 5'-triphosphate (ATP) sulfurylase, Bst polymerase v2.0 Warm Start, and 10× Bst buffer were purchased from NEB (Beijing, China). D-Luciferin sodium was obtained from Promega (Shanghai, China). AMV Re- 
verse Transcriptase (AMV) was purchased from Woosen Biotechnology (Shanghai, China). Droplet generation oil and stabilizer were obtained from Suzhou Rainsure Scientific Co. Ltd (Suzhou, Jiangsu, China). A DROPDx-2044HT digital PCR system was obtained from Suzhou Rainsure Scientific Co., Ltd. An ultra-weak luminescence analyzer was obtained from Jianxinlitou (Beijing, China). The all-in-one BZ-X800E fluorescence microimaging system was obtained from KEYENCE (Shanghai, China).

\subsection{Template and RNA Gradient Preparation}

The SARS-CoV-2 ORF1ab pseudoviral plasmid (target RNA) was used to prepare a 6-step concentration gradient $\left(10^{6}, 10^{5}, 10^{4}, 10^{3}, 10^{2}, 10\right.$ copies $\left./ \mathrm{mL}\right)$ for downstream analyses, and a negative control sample was also prepared (containing reaction mixture without target RNA). Ultrapure water was used as a diluent.

\subsection{Primer Design}

LAMP primers specific for the SARS-CoV-2 ORF1ab gene were obtained from a SARSCoV-2 Visual RT-LAMP Kit (Biolab, Beijing, China) and were based on the conserved ORF1ab gene sequence published in GenBank (GenBank: NC_045512.2). LAMP primers were designed using LAMP Designer 2.0, and included two internal primers (FIP/BJP), two external primers (F3/B3), and two Loop primers (LoopF/LoopB). For full primer details, see Table 5 .

Table 5. LAMP assay primer designs.

\begin{tabular}{ccc}
\hline Primer & Primer Sequence $\left(\mathbf{5}^{\prime} \mathbf{- \mathbf { 3 } ^ { \prime } )}\right.$ & Target Gene \\
\hline FIP & CACAACTACCACCCACTTTTGCCATGCAAGTTGAATC & \\
BIP & CGGACACAATCTTGCTAATAAGAAGTTGAATGTCTTCACC & \\
F3 & AACATGGAGGAGGTGTTG & ORF1ab \\
B3 & CAAGTAGAACTTCGTGCTG & \\
LoopF & GTGGTCCATTAGTAGCTATGT & \\
LoopB & CACTGTCTTCATGTTGTCG & \\
\hline
\end{tabular}

All primer pairs used for RT-LAMP assays were synthesized and HPLC-purified by Shanghai Biotech (Shanghai, China). We additionally confirmed the specificity of these primers and found that they were not prone to primer-dimer formation, tailing, or miscellaneous banding.

\subsection{The Feasibility of RT-LAMP Assay}

The RT- LAMP assays were performed with $500 \mu \mathrm{L}$ reaction mixtures containing $100 \mu \mathrm{L}$ of template pseudoviral plasmid reference RNA, $50 \mu \mathrm{L}$ of Bst polymerase v2.0 Warm Start $(8 \mathrm{U} / \mu \mathrm{L}), 70 \mu \mathrm{L}$ of $10 \times$ Bst buffer, $50 \mu \mathrm{L}$ of AMV $(5 \mathrm{U} / \mu \mathrm{L}), 5 \mu \mathrm{L}$ of each of the inner primers (FIP and BIP, $2.4 \mu \mathrm{mol} / \mathrm{L}$ ), $5 \mu \mathrm{L}$ of each of the outer primers (F3 and B3, $0.4 \mu \mathrm{mol} / \mathrm{L}$ ), $5 \mu \mathrm{L}$ of each loop primer (LF and LB, $1.2 \mu \mathrm{mol} / \mathrm{L}), 1 \mu \mathrm{L}$ of betaine $(0.8 \mathrm{~mol} / \mathrm{L})$, and $200 \mu \mathrm{L}$ of reaction mixture (0.3 mM deoxynucleotide triphosphates [dNTPs]). An optimized RT-LAMP mixture using dATP $\alpha$ S instead of dATP (Wuhu Huaren Science and Technology Co. Ltd., Wuhu, Anhui, China) was used for reactions, while normal monomers were used for all other dNTPs. An optimized RT-LAMP mixture using dATP $\alpha S$ instead of dATP (Wuhu Huaren Science and Technology Co. Ltd., Anhui, China). The reaction was monitored with a thermostat (Omega, UK) at $60{ }^{\circ} \mathrm{C}$ for $50 \mathrm{~min}$. The LAMP products $(2 \mu \mathrm{L})$ were separated with agarose gel electrophoresis and observed in a gel imaging system.

\subsection{RT-LAMP Bioluminescent Reagent Preparation}

RT-LAMP Bioluminescent reactions were conducted in a $1000 \mu \mathrm{L}$ volume composed of a $50 \mu \mathrm{L}$ RT-LAMP mixture and a $500 \mu \mathrm{L}$ bioluminescent mixture. 
The $500 \mu \mathrm{L}$ bioluminescent mixture included $20 \mathrm{mM}$ Tris-acetate ( $\mathrm{pH} 8.0$ ), $2 \mathrm{mM}$ $\mathrm{Mg}(\mathrm{Ac})_{2}, 0.4 \mathrm{mM}$ beetle luciferin potassium salt, $6 \mu \mathrm{M} \mathrm{KCl}, 10 \mathrm{mM}$ DTT, $5 \mu \mathrm{M}$ adenosine5'-O-phosphosulfate (APS), $1.46 \mathrm{ng} / \mathrm{mL}$ luciferase, and $0.2 \mathrm{U} / \mathrm{mL}$ ATP sulfurylase.

\subsection{SARS-CoV-2 ORF1ab Gene Detection}

\subsubsection{Bioluminescent Signal-Based Digital LAMP}

For digital LAMP assays, $10 \mu \mathrm{L}$ of the new or conventional RT-LAMP-BART reaction mixture, $70 \mu \mathrm{L}$ Droplet Generation Oil, and $10 \mu \mathrm{L}$ Stabilizer were added to the microfluidic chip. Droplets were generated using the DROPDx-2044HT digital PCR system (Suzhou Rainsure Scientific Co., Ltd., Suzhou, Jiangsu, China). The microfluidic chip matched with the digital PCR system was incubated for $35 \mathrm{~min}$ at $65^{\circ} \mathrm{C}$, after which the system was used to read the bioluminescent signal.

\subsubsection{Bioluminescent Signal-Based Simulated Digital LAMP}

The total RT-LAMP-BART reaction mixture volume $(1000 \mu \mathrm{L})$ was equally distributed across 96-well plates $(10.4 \mu \mathrm{L} /$ well) such that each well was equivalent to each droplet generated via the above approach. The plates were then placed in the BZ-X800E system (KEYENCE, Tokyo, Japan), and images and light intensity values were recorded following a 20-40 min incubation at $65^{\circ} \mathrm{C}$. This system utilized a combination of pixel binning and local CCD readings to achieve higher sensitivity.

\subsection{Simulated Digital LAMP Validation Using SARS-CoV-2 Orf1ab Visual RT-LAMP Kits}

Pseudoviral plasmid reference material and negative control derived from the SARSCoV-2 Orf1ab Visual RT-LAMP Kit (contained $10^{6}$ copies $/ \mu L=10^{9}$ copies $/ \mathrm{mL}$, Beijing, China) was tested via the simulated digital LAMP used in the present study.

The target concentration was prepared at a 2-step concentration gradient $\left(10^{4}, 10^{3}\right.$ copies $/ \mathrm{mL}$ ) and additionally verified via qPCR by Zoonbio Biotechnology Co. Ltd (Nanjing, Jiangsu, China). based upon directions provided with the SARS-CoV-2 Orf1ab Visual RTLAMP kit.

\subsection{The Specificity and Assessments of the Simulated Digital LAMP}

To determine the specificity of the developed method in this paper, contrived nasopharyngeal (NP) swabs $(n=18)$ and 2 common human coronavirus samples (strain 0C43, NL63), inactivated MERS-CoV and SARS-CoV-1 set as negative control were directly tested by simulated digital RT-LAMP assay and RT-qPCR to evaluate the specificity of the test. RT-qPCR were tested by the hospital of Nanjing.

\section{Conclusions}

Herein, through electrophoretogram of RT-LAMP for the detection of SARS-CoV-2 viral RNA, we found the $\mathrm{dATP} \alpha \mathrm{S}$ reacted well in RT-LAMP, which could take place of dATP. Then by coupled RT-LAMP with digital PCR, our digital LAMP system (Rainsuit, Suzhou, Jiangsu, China) with our optimized RT-LAMP-BART was able to achieve absolute quantification while conventional digital LAMP system (Rainsuit) was not. However, the digital LAMP system (Rainsuit) could not detect viral RNA in real-time and had a detection limit of $10^{4}$ copies $/ \mathrm{mL}$ owing to the limited use of sample copies analyzed in this reaction. The sensitivity of our simulated digital LAMP-BART approach was as low as 10 copies $/ \mathrm{mL}$, making this assay far more sensitive than digital LAMP and can be detected in real-time, yielding results within $20 \mathrm{~min}$. This simulated digital LAMP assay was also easier to conduct relative to digital LAMP as it did not require preparation of droplet generation or stabilizers. The sensitivity and stability of this simulated digital LAMP assay can also be further improved by increasing the reaction volume and the total number of wells used in a given analysis. 
As such, the simulated digital LAMP approach developed in the present study is highly sensitive, stable, and efficient, offering a means of reliably quantifying the absolute amount of target viral RNA present in a given sample of interest.

Author Contributions: Conceptualization, methodology, software, data curation, writing—original draft preparation: Z.F. and P.X.; visualization, investigation, validation: C.C.; supervision, software: R.W.; project administration, funding acquisition: P.X. All authors have read and agreed to the published version of the manuscript.

Funding: This work was funded by the National Natural Science Foundation of China, grant numbers 61971123 and 61571114.

Institutional Review Board Statement: Not applicable.

Informed Consent Statement: Not applicable.

Data Availability Statement: Not applicable.

Acknowledgments: The authors would like to thank all the reviewers who participated in the review and during the preparation of this manuscript.

Conflicts of Interest: The authors declare no conflict of interest.

\section{References}

1. Hui, D.S.; Azhar, E.I.; Madani, T.A.; Ntoumi, F.; Kock, R.; Dar, O.; Ippolito, G.; Mchugh, T.D.; Memish, Z.A.; Drosten, C.; et al. The continuing 2019-nCoV epidemic threat of novel coronaviruses to global health-The latest 2019 novel coronavirus outbreak in Wuhan, China. Int. J. Infect. Dis. 2020, 91, 264-266. [CrossRef] [PubMed]

2. Malik, Y.S.; Sircar, S.; Bhat, S.; Sharun, K.; Dhama, K.; Dadar, M.; Tiwari, R.; Chaicumpa, W. Emerging novel coronavirus (2019-nCoV)-Current scenario, evolutionary perspective based on genome analysis and recent developments. Vet. Q. 2020, 40, 68-76. [CrossRef] [PubMed]

3. Zhang, N.; Wang, L.; Deng, X.; Liang, R.; Su, M.; He, C.; Hu, L.; Su, Y.; Ren, J.; Yu, F.; et al. Recent advances in the detection of respiratory virus infection in humans. J. Med. Virol. 2020, 92, 408-417. [CrossRef] [PubMed]

4. Esbin, M.N.; Whitney, O.N.; Chong, S.; Maurer, A.; Darzacq, X.; Tjian, R. Overcoming the bottleneck to widespread testing: A rapid review of nucleic acid testing approaches for COVID-19 detection. RNA 2020, 26, 771-783. [CrossRef]

5. Service, R.F. Fast, cheap tests could enable safer reopening. Science 2020, 369, 608-609. [CrossRef]

6. Obande, G.A.; Singh, K.K.B. Current and future per-spectives on isothermal nucleic acid amplification technologies for diagnosing infections. Infect. Drug Resist. 2020, 13, 455-483. [CrossRef]

7. Metsky, H.C.; Freije, C.A.; Kosoko-Thoroddsen, T.S.F.; Sabeti, P.C.; Myhrvold, C. CRISPR-based COVID-19 surveillance using a genomically-comprehensive machine learning approach. BioRxiv 2020. [CrossRef]

8. Lucia, C.; Federico, P.B.; Alejandra, G.C. An ultrasensitive, rapid, and portable coronavirus SARS-CoV-2 sequence detection method based on CRISPR-Cas12. BioRxiv 2020. [CrossRef]

9. Broughton, J.P.; Deng, X.; Yu, G.; Fasching, C.L.; Servellita, V.; Singh, J.; Miao, X.; Streithorst, J.A.; Granados, A.; SotomayorGonzalez, A.; et al. CRISPR-Cas12-based detection of SARS-CoV-2. Nat. Biotechnol. 2020, 38, 870-874. [CrossRef]

10. Teng, F.; Guo, L.; Cui, T.; Wang, X.G.; Xu, K.; Gao, Q.; Zhou, Q.; Li, W.C. Detection: CRISPR-Cas12b-based DNA detection with sub-attomolar sensitivity and single-base specificity. Genome Biol. 2019, 20, 132. [CrossRef]

11. Schermer, B.; Fabretti, F.; Damagnez, M.; Di Cristanziano, V.; Heger, E.; Arjune, S.; Tanner, N.A.; Imhof, T.; Koch, M.; Ladha, A.; et al. Rapid SARS-CoV-2 testing in primary material based on a novel multiplex LAMP assay. MedRxiv 2020. [CrossRef] [PubMed]

12. Notomi, T.; Okayama, H.; Masubuchi, H.; Yonekawa, T.; Watanabe, K.; Amino, N.; Hase, T. Loop-mediated isothermal amplification of DNA. Nucleic Acids Res. 2000, 28, e63. [CrossRef] [PubMed]

13. Hardinge, P.; Murray, J.A.H. Reduced false positives and improved reporting of loop-mediated isothermal amplification using quenched fluorescent primers. Sci. Rep. 2019, 9, 7400. [CrossRef] [PubMed]

14. Hardinge, P.; Kiddle, G.; Tisi, L.; Murray, J.A. Optimised LAMP allows single copy detection of 35Sp and NOSt in transgenic maize using bioluminescent assay in real time (BART). Sci. Rep. 2018, 8, 17590. [CrossRef] [PubMed]

15. Kaneko, H.; Kawana, T.; Fukushima, E.; Suzutani, T. Tolerance of loop-mediated isothermal amplification to a culture medium and biological substances. J. Biochem. Biophys. Methods 2007, 70, 499-501. [CrossRef]

16. Tani, H.; Teramura, T.; Adachi, K.; Tsuneda, S.; Kurata, S.; Nakamura, K.; Kanagawa, T.; Noda, N. Technique for quantitative detection of specific DNA sequences using alternately binding quenching probe competitive assay combined with loop-mediated isothermal amplification. Anal. Chem. 2007, 79, 5608-5613. [CrossRef]

17. Kiddle, G.; Hardinge, P.; Buttigieg, N.; Gandelman, O.; Pereira, C.; McElgunn, C.J.; Rizzoli, M.; Jackson, R.; Appleton, N.; Moore, C.; et al. GMO detection using a bioluminescent real time reporter (BART) of loop mediated isothermal amplification (LAMP) suitable for field use. BMC Biotechnol. 2012, 12, 15. [CrossRef] 
18. Nagamine, K.; Watanabe, K.; Ohtsuka, K.; Hase, T.; Notomi, T. Loop-mediated isothermal amplification reaction using a nondena-tured template. Clin. Chem. 2001, 47, 1742-1743. [CrossRef]

19. Nzelu, C.O.; Cáceres, A.G.; Guerrero-Quincho, S.; Tineo-Villafuerte, E.; Rodriquez-Delfin, L.; Mimori, T.; Uezato, H.; Katakura, K.; Gomez, E.A.; Guevara, A.G.; et al. A rapid molecular diagnosis of cutaneous leishmaniasis by colorimetric malachite green-loop-mediated isothermal amplification (LAMP) combined with an FTA card as a direct sampling tool. Acta Trop. 2016, 153, 116-119. [CrossRef]

20. Asiello, P.J.; Baeumner, A.J. Miniaturized isothermal nucleic acid amplification, A review. Lab Chip 2011, 11, 1420-1430. [CrossRef]

21. Fei, Z.; Zhou, D.; Li, N.; Xiao, P. New bioluminescence pyrophosphate assay for high-sensitivity detection of food-borne pathogens. Luminescence 2020, 35, 355-364. [CrossRef] [PubMed]

22. Gandelman, O.A.; Church, V.L.; Moore, C.A.; Kiddle, G.; Carne, C.A.; Parmar, S.; Jalal, H.; Tisi, L.C.; Murray, J.A. Novel bioluminescent quantitative detection of nucleic acid amplification in real-time. PLoS ONE 2010, 5, e14155. [CrossRef] [PubMed]

23. Fushimi, T.; Miura, N.; Shintani, H.; Tsunoda, H.; Kuroda, K.; Ueda, M. Mutant firefly luciferases with improved specific activity and dATP discrimination constructed by yeast cell surface engineering. Appl. Microbiol. Biotechnol. 2013, 97, 4003-4011. [CrossRef] [PubMed]

24. Ronaghi, M.; Karamohamed, S.; Pettersson, B.; Uhlén, M.; Nyrén, P. Real-time DNA sequencing using detection of pyrophosphate release. Anal. Biochem. 1996, 242, 84-89. [CrossRef] [PubMed]

25. Kajiyama, T.; Kuwahara, M.; Goto, M.; Kambara, H. Optimization of pyrosequencing reads by superior successive incorporation efficiency of improved 2'-deoxyadenosine-5'-triphosphate analogs. Anal. Biochem. 2011, 416, 8-17. [CrossRef] [PubMed]

26. Rothberg, J.M.; Leamon, J.H. The development and impact of 454 sequencing. Nat. Biotechnol. 2008, 26, 1117-1124. [CrossRef] [PubMed]

27. Yang, Q.; Domesle, K.J.; Wang, F.; Ge, B. Rapid detection of Salmonella in food and feed by coupling loop-mediated isothermal amplification with bioluminescent assay in real-time. BMC Microbiol. 2016, 16, 112. [CrossRef]

28. Taylor, S.C.; Laperriere, G.; Germain, H. Droplet digital PCR versus qPCR for gene expression analysis with low abundant targets: From variable nonsense to publication quality data. Sci. Rep. 2017, 7, 2409. [CrossRef]

29. Zhong, Q.; Bhattacharya, S.; Kotsopoulos, S.; Olson, J.; Taly, V.; Griffiths, A.D.; Link, D.R.; Larson, J.W. Multiplex digital PCR: Breaking the one target per color barrier of quantitative PCR. Lab Chip 2011, 11, 2167-2174. [CrossRef]

30. Hindson, B.J.; Ness, K.D.; Masquelier, D.A.; Belgrader, P.; Heredia, N.J.; Makarewicz, A.J.; Bright, I.J.; Lucero, M.Y.; Hiddessen, A.L.; Legler, T.C.; et al. High-throughput droplet digital PCR system for absolute quantitation of DNA copy number. Anal. Chem. 2011, 83, 8604-8610. [CrossRef]

31. Hatch, A.C.; Fisher, J.S.; Tovar, A.R.; Hsieh, A.T.; Lin, R.; Pentoney, S.L.; Yang, D.L.; Lee, A.P. 1-Million droplet array with wide-field fluorescence imaging for digital PCR. Lab Chip 2011, 11, 3838-3845. [CrossRef] [PubMed]

32. Lv, D.F.; Ying, Q.M.; Weng, Y.S.; Shen, C.B.; Chu, J.G.; Kong, J.P.; Sun, D.H.; Gao, X.; Weng, X.B.; Chen, X.Q. Dynamic change process of target genes by RT-PCR testing of SARS-Cov-2 during the course of a coronavirus disease 2019 patient. Clin. Chim. Acta 2020, 506, 172-175. [CrossRef] [PubMed]

33. Fei, Z.; Zhou, D.; Dai, W.; Xiao, P. Rapid and highly sensitive detection of Escherichia coli O157: H7 in food with loop-mediated isothermal amplification coupled to a new bioluminescent assay. Electrophoresis 2020, 41, 1793-1803. [CrossRef] [PubMed]

34. Zhu, W.; Li, L.; Zhou, Z.; Yang, X.; Hao, N.; Guo, Y.; Wang, K. A colorimetric biosensor for simultaneous ochratoxin A and aflatoxins B1 detection in agricultural products. Food Chem. 2020, 319, 126544. [CrossRef] [PubMed]

35. Gadkar, V.J.; Goldfarb, D.M.; Gantt, S.; Tilley, P.A. Real-time detection and monitoring of loop mediated amplification (LAMP) reaction using self-quenching and de-quenching fluorogenic probes. Sci. Rep. 2018, 8, 5548. [CrossRef] 